\title{
Kırsal Kalkınma Projelerinde (Menengiç Ağaçlarının Aşılanarak Antep Fıstığı Üretilmesi) Yerel Halkın Katılımının Sağlanması Üzerine Bir Saha
} Araştırması: Manavgat Uzunlar Köyü

\author{
Research at Uzunlar Village/Manavgat on the Degree of Support and \\ Participation for Rural Development by Local People for a Project To Produce \\ Pistachio from Turpentine Trees through Grafting
}

\author{
Cemali SARI* \\ Ferhat TUNÇ** \\ İhsan BULUT ${ }^{* * *}$
}

$\ddot{O}_{z}$ : Turistik faaliyetlerin yoğunlaştığı Manavgat'ta ekonomi turizme dayanır. Bununla birlikte tarım sektörü de ilçe ekonomisi için önemlidir. Ancak ilçenin kuzey-kuzeydoğusunda kıyı gerisinde kurulmuş kırsal yerleşmeler ise bu iki önemli ekonomik girdiden yoksun durumdadır. Bu durum Manavgat'ta yıllar itibariyle iç kesimlerdeki yerleşmelerden nüfusun kıyıya yani turizm merkezine doğru göçüne neden olmaktadır. Kırsal kesimlerin farklı ekonomik potansiyellerinin tespiti ve bunların bir plan dâhilinde yerel halkın katılımı ile uygulamaya konulması bu nüfus hareketliliğini azaltabilir veya durdurulabilir. Kırsal kesimde orman içi ve kıyısı yerleşim alanlarında menengiç ağaçlarının aşılanarak Antep fistığı üretilmesi kırsal kalkınmada önemli bir adım olabilir. Bu araştırmada bölgenin orman ağaç türleri içerisinde oldukça yaygın olan menengiç ağaçlarının aşılanarak Antep fistığı üretilmesi ile ekonomiye kazandırılmasına dair Uzunlar köyü örneğinde kırsal nüfusun görüşlerinin belirlenmesi amaçlanmıştır. Uzunlar (Manavgat) köyünde 37 hane halkı ile yüz yüze görüşülerek 20 adet yarı yapılandırılmış görüşme sorusu cevaplamaları için verilmiş̧ir. Araştırmadan elde edilen verilerin analizinde kırsal nüfus, menengiç ağaçlarından Antep fistığı üretilebileceğine inandıklarını, projeyi olumlu bulduklarını, projede yer almak istediklerini ve projenin işlerlik kazanabileceğini belirtmişlerdir.

Anahtar sözcükler: Menengiç Ağacı, Antep Fıstığı, Kırsal Kalkınma Projeleri, Uzunlar Köyü Manavgat

Abstract: The economy of Manavgat relies upon tourism and agriculture plays a significant place in the town's economy. But the rural setting to the north and northeast of Manavgat, lacks the opportunity of participating in either of these elements of the local economy. Due to this situation, these country people migrate to the coastal region where the center of tourism is located. The determination and implementation of different economic potential in the countryside with both plan and participation from the local people may reduce or even stop this emmigration. The grafting for pistachio of turpentine trees which are dotted around the countryside in both forest and coastal region can be an important step for rural development. The aim of this survey was to gather information from the rural population, from Uzunlar village residents, about the grafting for pistachio of turpentine trees which are one of the most common trees in the region. 20 semi-structured interview questions were given to 37 local people in Uzunlar village. As the result of this survey, it was found that the local people believe that they can produce pistachio from grafting turpentine trees and they are positive about this project. They also indicate that they are willing to participate in this project and they believe it can work.

Keywords: Turpentine Tree, Pistachio, Rural Development Projects, Uzunlar Village, Manavgat

\footnotetext{
* Doç. Dr., Akdeniz Üniversitesi, Edebiyat Fakültesi, Coğrafya Bölümü, Antalya. cemsari@yahoo.com ** MA., Akdeniz Üniversitesi, Edebiyat Fakültesi, Coğrafya Bölümü, Antalya. ferhat.tunc@istek.org.tr *** Prof. Dr., Akdeniz Üniversitesi Edebiyat Fakültesi Coğrafya Bölümü, Antalya. ihsanbulut@akdeniz.edu.tr
} 


\section{Giriş}

Ülke sınırları içerisinde bölge, kent, kasaba ve köy gibi bir yerden diğerine yerleşmek amacıyla gerçekleştirilen nüfus hareketi (Üner 1972, 77) veya başka bir ifadeyle iktisadi, siyasi, sosyal nedenlerle ülke sınırları içerisinde bir bölge ya da kesimden başka bir bölge ya da kesime doğru akan nüfus hareketleri (TDK 2011) olarak ifade edilen iç göçün hikâyesi çok derinlere gitmektedir. Ülkemizde günümüzde yaşanan siyasi, sosyal, kültürel, ekonomik, kentsel ve yapısal birçok sorunun temelinde yatan nedenlerin ortaya çıkarılabilmesi, bunlara yönelik çözümler ve politikalar getirilebilmesi için, iç göçün arka planında yatan nedenlere bakmak gerekmektedir (Özdemir 2012, 2).

Türkiye'de 90'lı yılların başından beri hızla ivme kazanan turizm sektörü özellikle Akdeniz ve Ege kıyısında yer alan kırsal yerleşim alanlarının gerek sosyal gerekse ekonomik yapısını önemli ölçüde etkilemiştir. Bu sektörün getirdiği ekonomik iş olanakları ve sosyal anlamdaki bazı imkanlar kırsal alanda yaşayan üretken nüfusun sürekli olarak şehir merkezlerine göç etmelerine sebep olmuştur. Bu süreçte kentlere yönelen göçte, kentin çekiciliğinden çok kırsal alanın iticiliğinin büyük payı vardır (Keleş 1986, 135).

Kırsal kalkınma ülke ekonomisinin temeli niteliğindedir. Birincil ekonomik faaliyetlerin gerçekleştirildiği bu alanlarda yatırımların yetersiz kalması insanların bölgeyi terk etmesine ve hiç alışık olmadığı iş alanlarına yönelmelerine sebep olmaktadır. Kırsal kalkınmayı birçok bilim insanı çeşitli şekillerde ifade etmiştir. Zira kırsal yöreler, kendine özgü bir işleyiş yapısı olan kapalı ekonomiler halindedir. Kırsal yörelerde üretim ve tüketim piyasalarını birleştiren mübadele mekanizması yeterli derecede gelişmemiş olup, yapılan üretim büyük ölçüde kırsal toplumların ya da ailelerin kendi tüketim ihtiyaçlarında kullanılmaktadır. Kırsal yörelerde yaşayan insanlar geçimlerini genel olarak, toprağa dayalı bir üretim dalı olan tarımsal üretimden sağlamaktadır. Tarımsal üretim parasal gelir elde etmekten çok, günlük gıda güvenliğinin sağlanması için yapılmaktadır (Tolunay 2006, 121).

Bugüne kadar kırsal kalkınma anlayışı, kırsal alanda yaşayanların gelirlerini ve refahını artırmak, sosyal ve kültürel gelişmelerine katkıda bulunmak, kır-kent arasındaki farklılığ azaltarak kırsal kesimde kendi kendine yaşanabilir birimler oluşturmak ve kentlileşme olgusunu kıra yayarak yaşam düzeyini çağdaşlaştırmak gibi nedenlerle gerçekleştirilmiştir (Doğanay 1993, 33).

Araştırma sahası Uzunlar köyünün bağlı bulunduğu Manavgat, 2283 km²'lik yüzölçümüyle Antalya ilinin en büyük ikinci ilçesidir. İlçe nüfusu 2015 yılı itibariyle 222.419 kişidir. Sahil şeridinden itibaren, Toroslara kadar uzanan alan, tamamen ziraat alanı olup değişik bitkiler, meyveler ve ağaçlarla kaplıdır. Tarım arazilerinden sonra Toroslara çıkıldıkça maki ve orman alanları başlar. Toros dağları ise tamamen çalı ve maki türü bitkilerle kaplıdır.

İlçenin doğal yapısı kısmen tarıma uygun olup bu bölgelerde tarım gelişmiştir. Geri kalan bölgeler olan orman ve fundalık alanlar ve hayvancilığın geliştiği köyler olarak ayrılır. İlçe köylerinde büyük ve küçükbaş hayvan yetiştiriciliğinin yanında hububat, susam, karpuz yetiştiriciliği ve özellikle son yıllarda zeytincilik de giderek önem kazanmaktadır. Orman ürünleri işçiliği ve mevsimlik tarım işçiliği başlıca kazanç yolları olup sınırlı tarım arazilerinde hububat yanında son yıllarda kekik, kiraz ve ceviz gibi meyve yetiştiriciliği yapılmaya başlanmıştır.

Araştırma sahası olan Uzunlar köyü Manavgat'ın kuzeyinde, kıyı gerisinde, Toroslara geçiş sahasında kurulmuş bir köydür. Antalya iline 100, Manavgat ilçesine 21 km uzaklıktadır. Köyün toplam nüfusu 2014 yılı TÜİK verilerine göre 442'tir. Araştırma sahasında $135 \mathrm{ev,} 18$ ahır, 12 ağı1, 70 kümes bulunmaktadır. Küçükbaş hayvan sayısı yaklaşık 1200 civarında olup büyükbaş 
hayvan sayısı 75 adettir. Temel geçim kaynakları tarım ve hayvancılıktır.

Sahada son y1llarda turizm sektörüne işçi olarak nüfus hareketi gerçekleşmiş ve bölgenin sürekli azalan nüfusuna bağlı olarak mevcut imkanlar kullanılmamaya başlamıştır (Tablo 1.1). Zaten kısıtlı olan ekonomik uğraşlara gereken önem verilmeyerek burada bulunan yaşlı nüfus ekonomik zorluklarla karşılaşmıştır. Bölgede başlatılacak bir çalışma ile getirilecek ekonomik canlılık insanları üretime yönlendirerek köylerini terk etmelerini engelleyebilecektir.

Tablo 1.1. Yıllara Göre Nüfus Dağılışı (TÜİK verileri)

Uzunlar Köyü

\begin{tabular}{cc}
\hline Y1llar & Nüfus \\
\hline 2014 & 442 \\
\hline 2007 & 486 \\
\hline 2000 & 553 \\
\hline 1997 & 627
\end{tabular}

Köy halk1 ile yapılan yüz yüze görüşmelerde mevcut durumdan rahatsız olunduğu ve köyde iş imkânının artırılması yönünde çalışmaların başlatılması gerekliliği dile getirilmiştir. Menengiç ağaçlarının sadece hayvan otlatmada yem olarak kullanıldığı, ekonomik değere sahip olan Antep fistığına dönüştürülmesinin oldukça yararlı bir çalışma olacağı ifade edilmiştir. Hakim görüş ise yapılacak araştırmaların kamu kurum ve kuruluşlarının öncülüğünün önemli olduğudur. Bu araştırmada bölgenin menengiç popülasyonu belirleyebilmek için köy sınırlarındaki ormanlık sahanın 3 farklı yerinde 1'er hektarlık alan belirlenmiş, bu alanda menengiç sayımları yapılmıştır. Bu sayımlarda 1. alanda ortalama 380 adet, 2. alanda 450 adet, 3. alanda 420 adet olduğu tespit edilmiştir. Tüm alanda ortalama alınmış ve 2500-3000 kadar menengiç olduğu tahmin edilmektedir.

$\mathrm{Bu}$ araştırma gerek sahanın fiziki coğrafya şartlarının belirlenmesi gerekse köy halkın tutumlarının ölçülmesi yönüyle önemlidir. Özellikle kırsal alanlarda bu ve benzeri çalışmalar öncesinde kır nüfusunun tutumlarının belirlenmesi, bulgularından elde edilen verilerin uygulamaya geçirilmesi, kırsal nüfusun desteğinin sağlanması gerek sosyal gerekse ekonomik kalkınmada büyük katkı sağlayabilecektir.

\section{Araştırmanın Yeri ve} Sinırları

Araştırma sahasını oluşturan Uzunlar köyü, Antalya ili Manavgat ilçesi sınırları içerisinde yer alır. Sahanın kuzeyinde Taşkesiği Köyü, güneyinde Çavuşköy, doğusunda Halitağalar ve Kadılar köyü, batısında ise Haciobası ve Uzunkale köyü bulunur (Fig. 1).

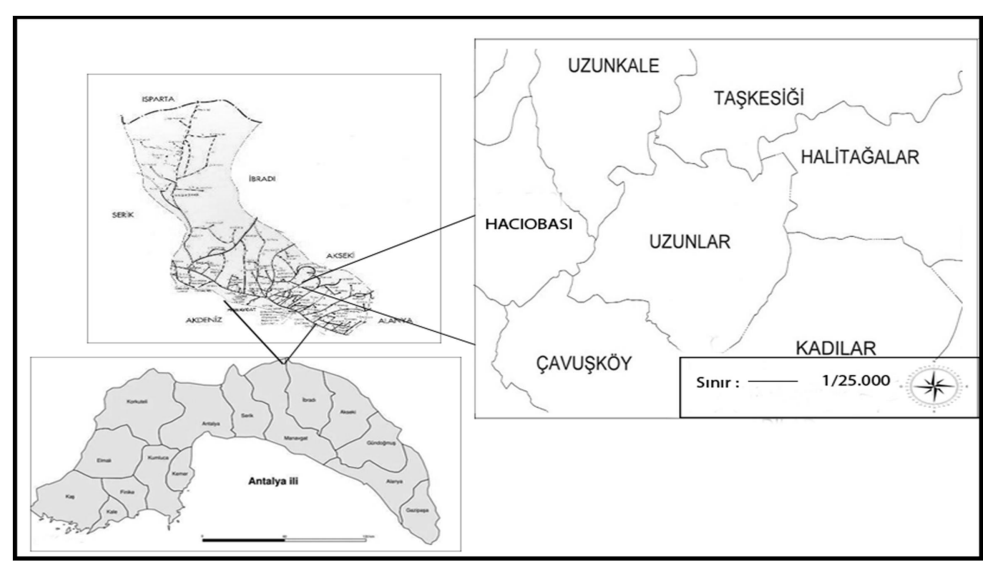

Fig. 1. Uzunlar Köyü Lokasyon Haritası 


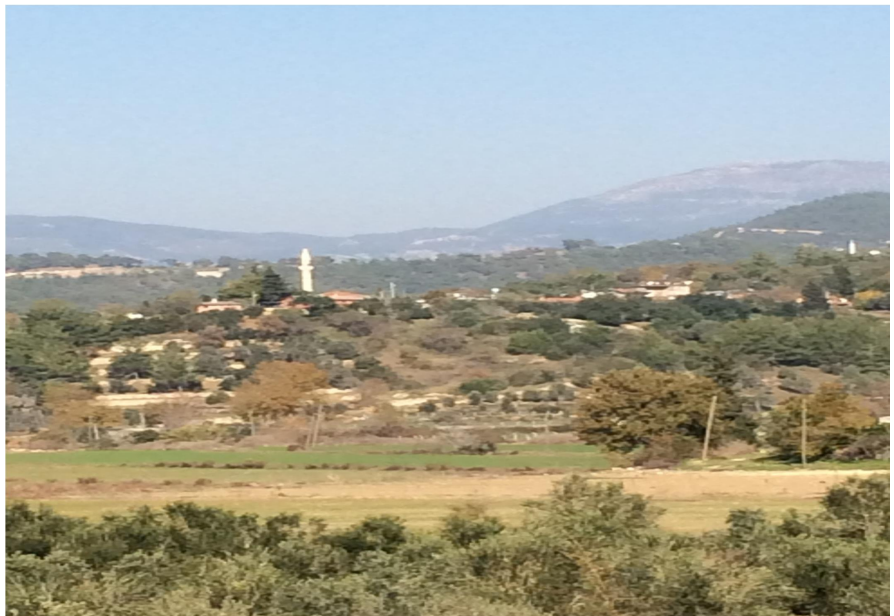

Fig. 2: Uzunlar Köyünden Genel Bir Görünüş

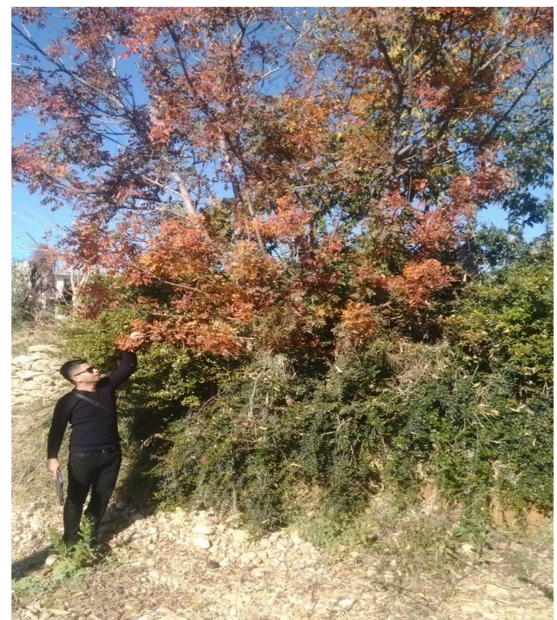

Fig. 3. Araştırma Sahasındaki bir Menengiç Ağacından Görüntü

\section{Araştırmanın Amacı ve Konusu}

Bu araştırmada temel amaç; bölgenin bitki örtüsü olan ve Uzunlar Köyü ekonomisine katkıs1 olmayan orman flora' larından menengiç (Pistacia terebinthus) ağacını aşılanarak Antep fistığı üretilmesi önerisi ve yerel halkın yaklaşımının belirlenmesidir. Bunun yanında; araştırma sahasındaki kırsal nüfusa alternatif kırsal kalkınma modelleri sunularak sahadan kıyı kesime doğru gerçekleşen hızlı nüfus hareketini azaltabilmesine ve/veya durdurabilmesine pozitif etki sağlayabilmektir.

\section{Araştırmanın Yöntemi}

Başlangıçta literatür taraması yapılmış, kamu kurum ve kuruluşları ile görüşülerek arazi gezi ve gözlem çalışmaları gerçekleştirilmiştir. Köy sınırlarındaki ormanlık sahanın 3 farklı yerinde 1'er hektarlık alanlar belirlenerek bu alanlarda menengiç ağacı sayımları yapılmış ve araştırma sahasının ortalama menengiç ağaç sayısı tespit edilmeye çalışılmıştır. Araştırma sahasında yüz yüze görüşme tekniği uygulandı. Bunun için yarı yapılandırılmış 20 tane soru hazırlandı. Bu sorular bölgede yaşayan 37 hane halkına yöneltildi. Elde edinilen veriler analiz edilerek ulaşılan bulgular sonucunda öneriler sunuldu.

\section{Bulgular ve Yorum}

Tablo 5.1. Araştırmaya Katılanların Yaş Dağılımı

\begin{tabular}{ccc} 
Yaş & Kişi & Yüzde(\%) \\
\hline $30-40$ & 8 & $\% 22$ \\
\hline $41-50$ & 9 & $\% 24$ \\
\hline $51-60$ & 9 & $\% 24$ \\
\hline $61-70$ & 4 & $\% 11$ \\
\hline $71-80$ & 7 & $\% 19$ \\
\hline Toplam & $\mathbf{3 7}$ & $\mathbf{\% 1 0 0}$
\end{tabular}

1. Kaç Yaşındasınız?

Araştırma sahasındaki katılımcıların \%22'si30-40, \%24'ü 4050, \%24'ü 50-60, \%11'i 60-70 ve \%19'u 70-80 yaş aralığındadır (Tablo 5.1). Katılımcıların \%78'i 40 yaş üzerinde olup bu durum araştırma sahası nüfusunun orta yaş, üretken ve yaşlı nüfustan oluştuğunu göstermektedir. 
Tablo 5.2. Araştırmaya Katılan Nüfusun Eğitim Düzeyi

\begin{tabular}{ccc} 
Okul & Kişi & Yüzde (\%) \\
\hline İlkokul & 31 & $\% 84$ \\
\hline Lise & 4 & $\% 11$ \\
\hline Lisans & 2 & $\% 5$ \\
\hline Toplam & 37 & $\% 100$
\end{tabular}

2. Eğitim Düzeyiniz Nedir?

Katılımcıların \%84'ü ilkokul, \%11'i lise, \%5'i ise lisans mezunudur (Tablo 5.2). Lise ve lisans mezunlarının da varlığ 1 böyle projenin uygulanma ve köye entegre olmasında destekleyici bir unsur olarak düşünülebilir.

Tablo 5.3: Ankete Katılanların Aile Birey Sayısı

\begin{tabular}{ccc} 
Aralık & Kişi & Yüzde \%) \\
\hline $1-3$ & 9 & $\% 24$ \\
\hline $4-7$ & 21 & $\% 57$ \\
\hline $8-11$ & 5 & $\% 14$ \\
\hline $12-15$ & 2 & $\% 5$ \\
\hline Toplam & 37 & $\% 100$
\end{tabular}

3. Aileniz kaç kişiden oluşuyor?

Sahadaki katılımcıların aile birey sayısı \%24'ü 1-3, \%14'ü 4-7, \%5'i 8-11, \%57'si 12-15 kişi aralığındadır (Tablo 5.3). $\mathrm{Bu}$ durum Türkiye'deki kırsal aile modellerine benzer nitelikte, yani kalabalıktır.

Tablo 5.4. Aile Bireylerinin Yaşam Yeri

\begin{tabular}{ccc} 
& Kişi & Yüzde (\%) \\
\hline Evet & 11 & $\% 30$ \\
\hline Hayır & 26 & $\% 70$ \\
\hline Toplam & 37 & $\% 100$
\end{tabular}

4. Aile bireylerinizin hepsi köyünüzde mi yaşıyor?

Görüşmeyi kabul edenlerden 37 kişiden sadece 11 kişinin aile bireylerinin tamamı araştırma sahasında ikamet etmektedir. 26 Katılımcının aile bireyi ise saha dıșında farklı bir yerleşim alanında ikamet etmektedir. Bu durum katılımcıların \%70'i yani her 10 aileden 7'sinde aile bireylerden herhangi birinin farklı bölgelere özellikle kıyı kesimine göç ettiğini göstermektedir (Tablo 5.4)

Tablo 5.5. Köyün Dışarıdan Göç Alma Durumu

\begin{tabular}{lcc} 
& Kişi & Yüzde(\%) \\
\hline Evet & 8 & \%22 \\
\hline Hayır & 29 & \%78 \\
\hline Toplam & 37 & $\% 100$
\end{tabular}

5. Köyünüz dışarıdan göç alıyor mu?

Yukarıdaki şekil görüldüğü gibi ankete katılanların \%78'i köylerinin göç verdiğini ifade etmiş, \%22'si ise vermediğini ifade etmişlerdir (Tablo 5.5). Bu durum sahanın yıllara göre nüfus dağılışı azalışın nedenlerini de destekler niteliktedir.

Tablo 5.6. Köyün Göç Verme Durumu

\begin{tabular}{lcc} 
& Kişi & Yüzde(\%) \\
\hline Veriyor & 34 & $\% 92$ \\
\hline Vermiyor & 3 & $\% 8$ \\
\hline Toplam & 37 & $\% 100$
\end{tabular}

6. Köyünüz dışarıya göç veriyor mu?

Ankete katılanların \%8'i köylerinin göç vermediğini \%92'si ise köylerinin göç verdiğini ifade etmiştir (Tablo 5.6). Katılımcıların büyük bir bölümü köylerinin göç verdiğini ifade ederek yeni çalışmaların başlatılmasının gerekliliğine işaret etmişlerdir.

Tablo 5.7: Köyün Göç Verme Sebepleri

\begin{tabular}{lcc} 
Nedenler & Kişi & Yüzde(\%) \\
\hline Ekonomik sebep & 30 & $\% 81$ \\
\hline Eğitim-ulaşım & 7 & $\% 19$ \\
\hline Toplam & 37 & $\% 100$
\end{tabular}

7. Köyünüzün dışarıya göç vermesinin sebepleri nelerdir?

Tabloda da görüldüğü gibi ankete katılanların \%81'i ekonomik sebeplerle iş olanağının köylerinde yetersiz olması nedeniyle göç vermektedir. \%19'u ise eğitim ve ulaşım zorluğu gibi nedenlerle göç verdiklerini ifade etmişlerdir (Tablo 5.7). 
Tablo 5.8. Geçim Kaynakları

\begin{tabular}{lcc} 
Geçim kaynakları & Kişi & Yüzde (\%) \\
\hline Tarım & 8 & $\% 22$ \\
\hline Hayvancılık & 5 & $\% 13$ \\
\hline Tarım-hayvancılık & 11 & $\% 30$ \\
\hline Sezonluk işçi & 5 & $\% 14$ \\
\hline Emekli & 5 & $\% 13$ \\
\hline İşsiz & 3 & $\% 8$ \\
\hline Toplam & 37 & $\% 100$
\end{tabular}

8. Geçiminizi ne ile sağlıyorsunuz?

Görüşmeye katılanların \%65'i birincil ekonomik sektörler olan tarım ve hayvancılık ile uğraşmakta, sezonluk işçi (turizm) ve emeklilerin oranı aynı (\%1314) işsiz oranı ise \%8'dir (Tablo 5.8). Bu durum yapılacak olan çalışma için köylünün tarımsal bilgi birikimine sahip olduğu kanıtlar niteliktedir.

Tablo 5.9. Y1llık Gelir Düzeyi

\begin{tabular}{lcc} 
Y1ll1k gelir (Bin TL) & Kişi & Yüzde (\%) \\
\hline $5-15$ & 23 & $\% 64$
\end{tabular}

\begin{tabular}{lcc}
\hline $5-15$ & 23 & $\% 64$ \\
\hline $15-25$ & 6 & $\% 17$ \\
\hline $25-35$ & 2 & $\% 5$ \\
\hline $35-50$ & 3 & $\% 8$ \\
\hline Belirtilmemiş & 2 & $\% 6$ \\
\hline Toplam & 37 & $\% 100$
\end{tabular}

9. Ortalama y1llik geliriniz ne kadar?

Kat1lımcıların \%64'ü 5-15, \%17'si 15-25, \%5'i 25-35, $\% 8$ i 35-50 bin TL y1ll1k ortalama gelire sahiptir (Tablo 5.9). Bu oranlara bakıldığında gelir düzeylerinin düşük olduğu göze çarpmaktadır. \%64 gibi bir oranın ortalama asgari ücretin altında yıllık gelire sahip olduğu gözlenmiştir.

Tablo 5.10. Gelirin Yeterlilik Durumu

\begin{tabular}{lcc} 
Gelirin yeterliliği & Kişi & Yüzde (\%) \\
\hline Yetiyor & 11 & $\% 30$ \\
\hline Yetmiyor & 26 & $\% 70$ \\
\hline Toplam & 37 & $\% 100$
\end{tabular}

10. Y1llık geliriniz geçiminiz için yeterli mi?

Katılımciların \%30'u gelirinin yettiğini, \%70'i ise yetmediğini söylemiştir (Tablo 5.10). Sahadan hızlı bir göç hareketinin gerçekleşmesi bu durumun temel sebebi

olarak düşünülebilir.

Tablo 5.11. Sosyal Güvence Durumu

\begin{tabular}{lcc} 
Sosyal güvence & Kişi & Yüzde (\%) \\
\hline Var & 28 & $\% 76$ \\
\hline Yok & 9 & $\% 24$ \\
\hline Toplam & 37 & $\% 100$
\end{tabular}

11. Sosyal güvenceniz var mı?

Katılımciların \%76's1 sosyal güvencesinin olduğunu, \%24'ü ise olmadığını ifade etmiştir (Tablo 5.11). \%24'ü yani her dört kişiden birinin ise sosyal güvenceye sahip

olmaması oldukça yüksek bir orandır.

Tablo 5.12. Başka Bir Yerde Yaşama İsteği

\begin{tabular}{lcc} 
& Kişi & Yüzde (\%) \\
\hline Evet & 11 & $\% 30$ \\
\hline Hayır & 26 & $\% 70$ \\
\hline Toplam & 37 & $\% 100$
\end{tabular}

12. İmkanınız olsa başka bir köy, kasaba veya şehirde yaşamak ister misiniz? 5.12). Bu durum köylerine olan sevgilerini göstermekte ve gerçekleştirilecek bir kalkındırma projesinin köylerine olan bağlılıklarını daha da kuvvetlendireceğini kanıtlamaktadır.

Tablo 5.13. Farklı Ekonomik Faaliyete Gösterilen İlgi

\begin{tabular}{lcc} 
& Kişi & Yüzde (\%) \\
\hline Evet & 29 & $\% 78$ \\
\hline Hayır & 8 & $\% 22$ \\
\hline Toplam & 37 & $\% 100$
\end{tabular}

13. Köyünüzde farklı faaliyet alanları olsa ilgi gösterir misiniz?

Ankete katılanların \%78'i farklı bir ekonomik faaliyete katılmak istediğini \%22'si ise katılmak 
istemediğini dile getirmiştir (Tablo 5.13). Görüldüğü gibi katılımcılardan, farklı ekonomik faaliyetleri destekleyen ve bu faaliyetlere katılmak isteyenlerin oranı oldukça yüksektir. Bu durum aslında yapılabilecek çalışmanın başarıya ulaşmasında önemli kıstaslardan bir tanesidir.

Tablo 5.14. Farklı Ekonomik Faaliyetlerin Yapılabilirliği

\begin{tabular}{lcc} 
& Kişi & Yüzde (\%) \\
\hline Yapılabilir & 13 & $\% 35$ \\
\hline Yapılamaz & 8 & $\% 22$ \\
\hline Bilmiyorum & 16 & $\% 43$ \\
\hline Toplam & 37 & $\% 100$
\end{tabular}

14. Köyünüzde mevcut ekonomik uğraşlar dışında farklı ekonomik faaliyetler yapılabilir?

Katılımcıların \%43'ü köylerinde farklı bir ekonomik faaliyetin yapılabilirliği hakkında herhangi bir yorum yapamamışlardır. \% 35'i yapılabileceğini ifade ederken \%22'lik kesim köylerinin tüm ekonomik potansiyellerini kullandıklarını düşünmektedir (Tablo 5.14).

Tablo 5.15. Ormanlık Sahadan Yararlanma

\begin{tabular}{lcc} 
& Kişi & Yüzde (\%) \\
\hline Evet & 33 & $\% 89$ \\
\hline Hayır & 4 & $\% 11$ \\
\hline Toplam & 37 & $\% 100$
\end{tabular}

15. Köyünüz sınırlarına dahil olan ormanlık sahalardan yararlaniyor musunuz?

Ankete katılanların \%89'u ormanlık alandan çeşitli amaçlarla yararlandıklarını \%11'i ise herhangi bir şekilde

kullanmadıklarını ifade etmişlerdir (Tablo 5.15). Görüldüğü gibi orman, köylünün hayat sahası içindedir. Ancak önemli olan zaten kullanılıyor olan bu sahanın daha yararlı ve işlevsel özellikle değerlendirilmesidir.

Tablo 5.16. Ormandan Yararlanma

\begin{tabular}{lcc} 
Yararlanma şekli & Kişi & Yüzde (\%) \\
\hline Yakacak & 22 & $\% 59$ \\
\hline Otlatma & 11 & $\% 30$ \\
\hline Avlanma & 4 & $\% 11$ \\
\hline Toplam & 37 & $\% 100$
\end{tabular}

16. Ormandan ne tür fayda elde ediyorsunuz?

Ankete katılan köylüler ormanı yakacak (\%59'u), hayvan otlatma (\%30'u) ve avlanma (\%11'i) şeklinde ormandan yararlanmaktadır (Tablo 5.16). Ormanlık sahadan ilkel yöntemlerle ve ekosisteme zarar vererek yararlanılmakta olup bu durum alanda ilerleyen süreçte ciddi problemler yaratabilir.

Tablo 5.17. Menengiç Ağacından Antep Fıstığı Üretiminin Bilinirliği

\begin{tabular}{|c|c|c|c|}
\hline & Kişi & Yüzde $(\%)$ & Orman ağaç türlerinden olan menengiç ağaçlarının \\
\hline$\overline{\text { Biliyordum }}$ & 14 & $\% 38$ & Iması ile Antep fistığı yetiştirildiğini biliy \\
\hline Bilmiyordum & 23 & $\% 62$ & $\mathrm{~m}$ \\
\hline Toplam & 37 & $\% 100$ & c a ăacina Anter \\
\hline
\end{tabular}
aşılanabileceğini biliyorken \%62'lik oranı bu konuda herhangi bir bilgiye sahip değildir (Tablo 5.17). Yüksek bir oranın bu bilgiyi ilk defa duyması projeye gösterilecek ilgiyi de arttıracaktır. Çünkü çoğu zaman yeni olan bir uygulama insanlara ilginç gelerek onları deneyimlemeye itecektir.

Tablo 5.18. Antep Fistığı Üretimi İsteği

\begin{tabular}{|c|c|c|c|}
\hline Üretim isteği & Kişi & | Yüzde (\%) & \multirow{2}{*}{$\begin{array}{l}\text { 18. Köyünüz ormanlık sahalarında bu tür bir üretim } \\
\text { yapmak ister misiniz? }\end{array}$} \\
\hline Evet & 31 & $\% 84$ & \\
\hline Hayır & 6 & $\% 16$ & \multirow{2}{*}{$\begin{array}{l}\text { Görüssmeye katılan nüfusun } \% 84 \text { 'ü bu tip bir faaliyete } \\
\text { katılmak istediğini ifade ederken } \% 16 \text { 's1 istemediğini }\end{array}$} \\
\hline Toplam & 37 & $\% 100$ & \\
\hline
\end{tabular}


böyle bir faaliyet için hazır olduğunu ifade etmişlerdir.

Tablo 5.19. Çalışmanın Başarıya Ulaşabilirliği

\begin{tabular}{l|c|c} 
Başarı & Kişi & Yüzde (\%) \\
\hline Olur & 35 & \%95 \\
\hline Olmaz & 2 & \%5 \\
\hline Toplam & 37 & $\% 100$
\end{tabular}

19. Devlet desteği ile yapılacak bu tür bir çalışma sizce başarılı olur mu?

Devlet desteği ile yapılabilecek böyle bir çalışmanın başarılı olacağına katılımcıların \%95'i olumlu tepki verirken $\% 5$ 'i ise başarılı olunamayacağını söylemiştir (Tablo 5.19). Bu durum çalışmanın başarıya ulaşılacağına dair katılımcıların inancı oldukça yüksektir.

Tablo 5.20. Çalışmadan Köylünün Beklentisi

\begin{tabular}{l|c|c} 
Beklentiler & Kişi & Yüzde (\%) \\
\hline Eğitim & 14 & $\% 38$ \\
\hline Ekonomik destek & 11 & $\% 30$ \\
\hline Beklentim yok & 12 & $\% 32$ \\
\hline Toplam & 37 & $\% 100$
\end{tabular}

20. Böyle bir çalışmaya katılmanız için sizin beklentileriniz nelerdir?

$\mathrm{Bu}$ çalışmayı destekleyen katılımcıların isteği, öncelikle konu hakkında eğitim (\%38) alarak bilinçlenmek ve akabinde kredi desteği (\%30) ile çalışmalara başlamak şeklinde olmuştur. Ankete katılanların \%32'si ise böyle bir çalışmaya katılmak için herhangi bir talepte bulunmamıştır (Tablo 5.20).

\section{Tartışma ve Sonuç}

Arazi gözlemleri ve ilgili kurum ve kuruluşlarla yapılan görüşmelerde elde edilen veriler sonunda araştırma sahasının orman flora'sında (maki) aşılanabilecek 2500-3000 menengiç ağacı olduğu tahmin edilmektedir. Bölgenin orman sahasındaki aşılanabilecek menengiç ağacı sayısı köylünün ekonomik girdi sağlayabileceği seviyededir.

Uzunlar köyünde, rastlantısal (Random) olarak seçilen 37 kişiyle yapılan yüz yüze görüşmede katılımcıların \%95'i bu çalışmayı/projeyi desteklemektedir. Araştırma sahasının nüfusu yıllar itibariyle azalmakta ve turizm sektöründe sezonluk işçi olarak çalışabilmek için kıyı kesimine göç etmektedir. Yapılan görüşmelerde köy nüfusunun büyük bölümünü yaşlıların oluşturduğu görülmüştür. Bu nüfusun da bu genç nüfusun göçünden rahatsız oldukları gözlemlenmiştir. Katılımcılar böyle bir çalışmanın köylerine değer katacağını ve ekonomik çeşitliliği arttırabileceğinden göç vermeyip hatta alabileceğini de ifade etmişlerdir. Göç sebeplerine bakıldığında \%81 gibi yüksek bir oranın 'ekonomik nedenlerle' gerçekleşmesi sahada gerçekleştirilecek projenin gerekliliğini ortaya koymaktadır.

Katılımcılar, bu zamana kadar hiçbir devlet kuruluşu tarafindan böyle bir çalışmanın yapılmadığını ve bu çalışmanın başarıya ulaşması halinde birçok köy ve köy altı yerleşmesine örnek teşkil edebileceğini ifade etmişlerdir.

Yapılan araştırmada Uzunlar köyünde ekonomik geçim kaynağını tarım ve hayvancık oluşturmaktadır. Sahanın bu özelliği yani tarımın hakim ekonomik faaliyet kolu olması gerçekleştirilecek Antep fistığı tarımının entegrasyonunu kolaylaştıracak pozitif bir etkendir.

Zaten köylüler genel olarak yakacak ve hayvan otlatma şeklinde ormandan yararlanmaktadır. Orman Uzunlar köyü halkına kısıtlı bir ekonomik destek sağlasa da bilinçsizce bunun yaygınlaştırılması Antep fıstı̆̆ üretimi gibi farklı projelerin hayata geçirilmesine engel değildir. Katılımcıların yüksek bir oranının (\%78) yapılabilecek farklı bir ekonomik faaliyetli desteklemesi, sahada 'menengiç ağaçlarının aşılanarak Antep fıstığına dönüştürülmesi' çalışmasının başarıya ulaşmasında önemli kıstaslardan biri olarak kabul edilebilir. 


\section{KAYNAKÇA}

Doğanay F. (1993a). Kırsal Kalkınma. Ankara 1993.

Doğanay F. (1993b). Merkez Köyler, Sosyal Planlama Genel Müdürlüğü Planlama Dairesi Başkanlı̆̆l. Ankara 1993.

Özdemir H. (2012). “Türkiye’de İç Göçler Üzerine Genel Bir Değerlendirme”. Akademik Bakış Dergisi 30 (2012) 1-18. Kaynak: http://www.akademikbakis.org/eskisite/30/11.pdf

TDK (2011). Türk Dil Kurumu. Büyük Türkçe Sözlük.

Kaynak: http://tdkterim.gov.tr/bts Erişim Tarihi: 18.02.2007.

Tolunay A. \& Akyol A. (2006). "Kalkınma ve Kırsal Kalkınma: Temel Kavramlar ve Tanımlar". Süleyman Demirel Üniversitesi Orman Fakültesi Dergisi A/2 (2006) 116-127.

Keleş R. (1986). Hızlı Şehirleşmenin Yarattı̆̆ Ekonomik ve Sosyal Sorunlar. İstanbul 1986.

Üner S. (1972). Nüfus Bilim Sözlüğ̈̈. Ankara 1972.

https://tr.wikipedia.org/wiki/Manavgat18.01.2016.

https://tr.wikipedia.org/wiki/Uzunlar,_Manavgat 11.02.2016.

http://www.tuik.gov.tr/UstMenu.do?metod=temelist 05.05.2016. 